\title{
A Proposal of Potentially Meaningful Material for Teaching of Vector Mechanics
}

\author{
Bruno Nunes Myrrha Ribeiro1, Carlos Vitor de Alencar Carvalho1,2 \\ ${ }^{1}$ Geraldo di Biase University Center, Barra do Piraí, Brazil \\ ${ }^{2}$ State University Center of Western Rio de Janeiro, Severino Sombra University, Vassouras, Brazil \\ Email: myrrhaugb@gmail.com, brunomyrrha@ugb.edu.br, carloscarvalho@uezo.ri.gov.br, cvitorc@gmail.com
}

Received 30 August 2014; revised 28 September 2014; accepted 16 October 2014

Academic Editor: Joseph Claudet, Texas Tech University, USA

Copyright (C) 2014 by authors and Scientific Research Publishing Inc.

This work is licensed under the Creative Commons Attribution International License (CC BY).

http://creativecommons.org/licenses/by/4.0/

c) (i) Open Access

\section{Abstract}

This paper presents didactic solutions to the Vector Mechanics subject, which aims to teach the calculation and the representation of the acting forces on a given particle in space. It is about developed and applied activities in GeoGebra software, called potentially meaningful materials. The whole proposal was based on MLT-Meaningful Learning Theory, proposed by David Ausubel, in order to contribute to a more efficient learning in general disciplines of engineering courses.

\section{Keywords}

Vector Mechanics, GeoGebra, Meaningful Learning, Potentially Meaningful Teaching Material, Potentially Meaningful Teaching Unit

\section{Introduction}

One of the difficulties presented in teaching mechanical vector is the visualization and interactivity issue. The use of static resources, such as lecture classes and the traditional media used, most often, does not allow a satisfactory teaching and learning of the content. An effective learning of the content is important for the engineers during the training, but the methodological alternatives that can provide the assimilation of the content in the easiest way, in most of the times are not available in the courses for teachers.

GeoGeabra software, which is a dynamic geometric environment that allows the interactive exploration of algebraic and geometric concepts, was used in the development and proposal of didactic solutions for disciplines 
in General Mechanical Engineering courses, developing activities in the form of computation tools, so-called potentially meaningful material. It was observed as necessary conditions in MLT-Meaningful Learning Theory, theoretical basis that contextualizes that new knowledge starts from the interaction with the previous cognitive structure of the individual knowledge.

Nowadays, computerization was not contested anymore, because the first contact with the computer technologies came from childhood; however, it was observed that lately technological insertions came from previous experiences at school.

\section{The Augmented Reality (AR)}

The applied IT to education approaches relative concepts about learning, philosophy knowledge, domination of technological education and pedagogical practice. According to Almeida (2000), his classification is conditioned to a couple of approaches: instructionist and constructionist. Almeida (2000) thus observes that knowledge transmissions in view of the applied IT to education are characterized in two areas: Computer Instruction Assistance and Computer Intelligent Instruction Assistance.

According to Valente (1999), the development of the cycle "description-execution-reflection-debug-description" in educational software is a core value in the assimilation of new information by the student. The description consists in describing the problem; the execution is the step that determines a true and instantaneous feedback; the reflection provides a note about what was done and debug is the procedure when the individual searches for the new. From this, the cycle "description-execution-reflection-debug-description" is held again (Figure 1).

\section{Vector Mechanics}

Mechanics is an applied science that analyses physical phenomena that characterizes the action of forces acting on bodies; it is subdivided into the mechanics of rigid body, the deformable body and fluids, based on the structured analysis of the following concepts of magnitudes: space, time, mass and strength (Beer, Johnston, \& Eisenberg, 2006).

It is crucial to highlight that the development of the this paper applies concepts from resultant forces on bodies at rest, considered perfectly rigid and represented by vectors in the plan and in space, under the complexity of the Static topics, a subarea of Mechanics of rigid bodies. Thus, it was selected as the aim of this paper, the rectangular components of a force in space (Figure 2).

\section{Mainingful Learning Theory}

The meaningful learning theory (MLT), proposed by David Joseph Ausubel is presented in the form of conceptual map as shown in Figure 3, defining that, learning new knowledge comes from the interaction with the previous knowledge in the cognitive structure of the learner. This concept is called "subsume" (Figure 3).

When it comes to teaching and learning, it is important to note as necessary conditions to a meaningful learning, the potentially meaningful material and the predisposition to learn (Moreira \& Mansini, 2011). The Potentially significant materials developed will be presented in the next section.

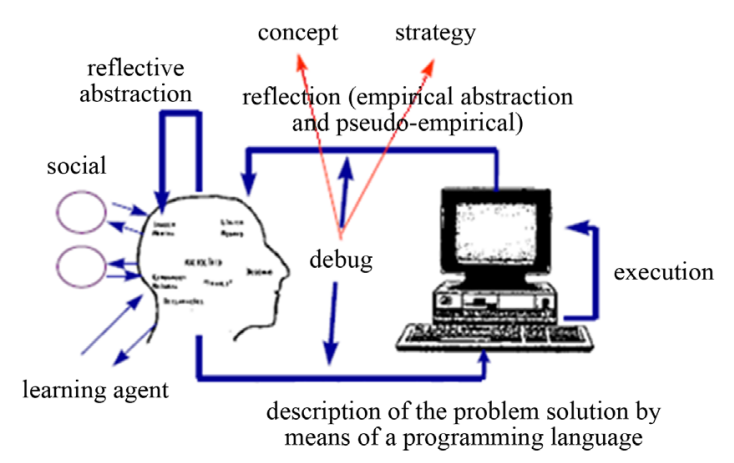

Figure 1. Cycle “description-execution-reflection-debug-description”. Extracted from reference: Valente (1999). 


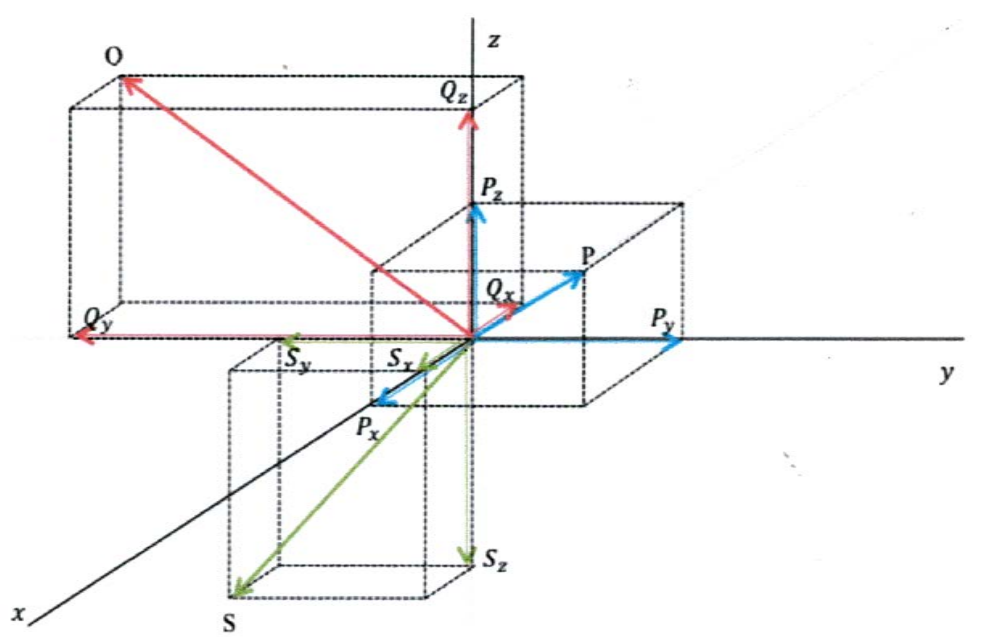

Figure 2. Rectangular components of various forms in space.

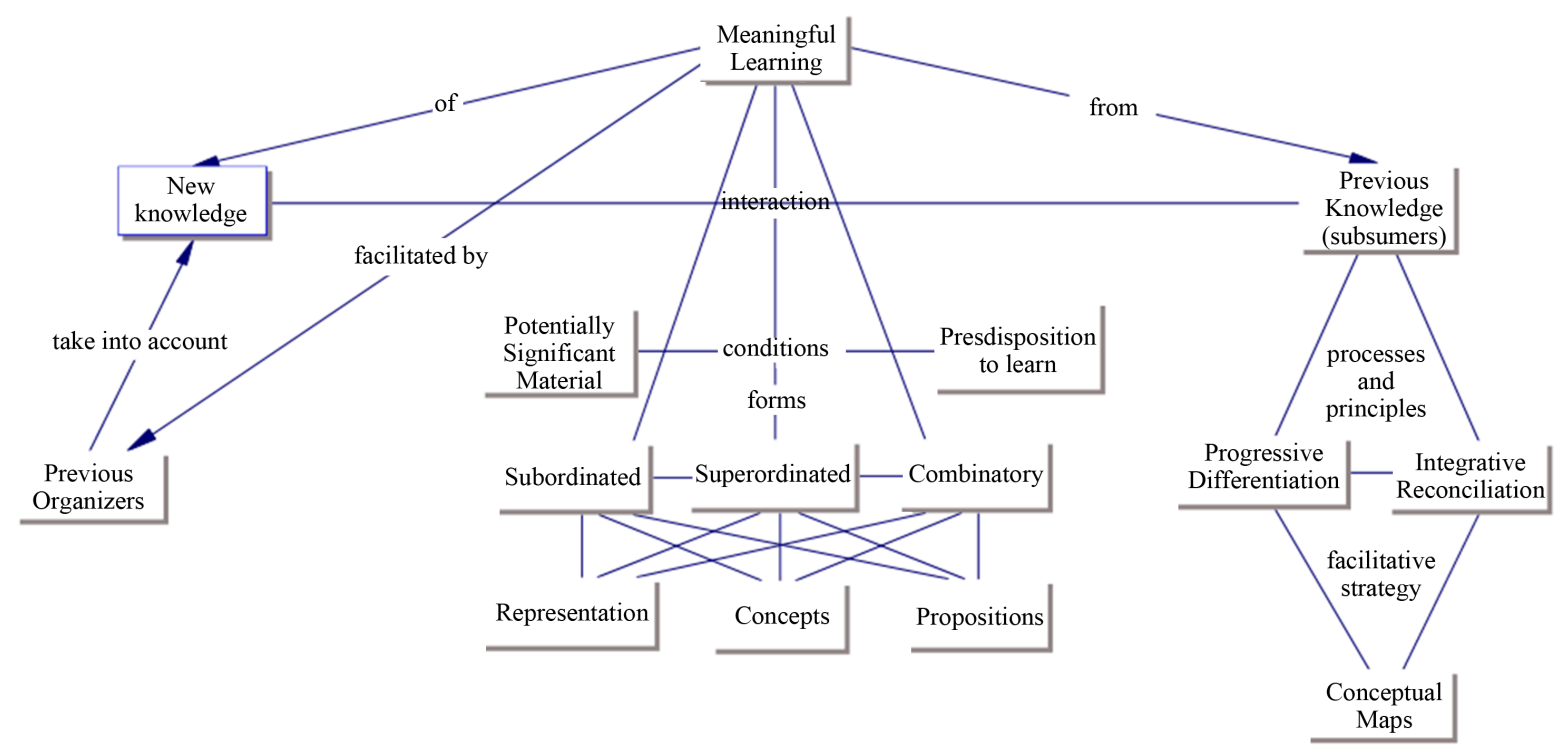

Figure 3. Meaningful learning theory. Extracted from reference: Moreira (2009).

\section{The Potentially Meaningful Material in Vectorial Mechanics Teaching}

This entire work was developed in EERL-Engineering Education Research Laboratory

(http://labpee.wordpress.com/) (LPEE (Portuguese): Laboratório de Pesquisa em Educação em Engenharia), a laboratory for research and development of didactic solutions to engineering teaching.

Based on learning theory, potentially meaningful material was developed in GeoGebra software, a dynamic geometric environment that allows the exploration of geometrical and algebraic concepts in interactive forms. All implementations of interactive activities were developed in a constructionist strand, with CAI characteristics and exercises of classificatory approach, practical exercises and simulation, allowing the application cycle description-execution-reflection-debug-description, relating to educational tools. From a canonic basis, a space is simulated in a plan, developing the decomposition of three-dimensional vector forces (Figure 4).

Sequentially, it is presented the material that applies the calculation of the acting forces that results with a variable height tower, allowing the alteration of the tower image, which contextualizes the application of the study (Figure 5 and Figure 6).

The potentially meaningful material is available on the website LPEE-Research Laboratory of Engineering Education for the national and international community. 


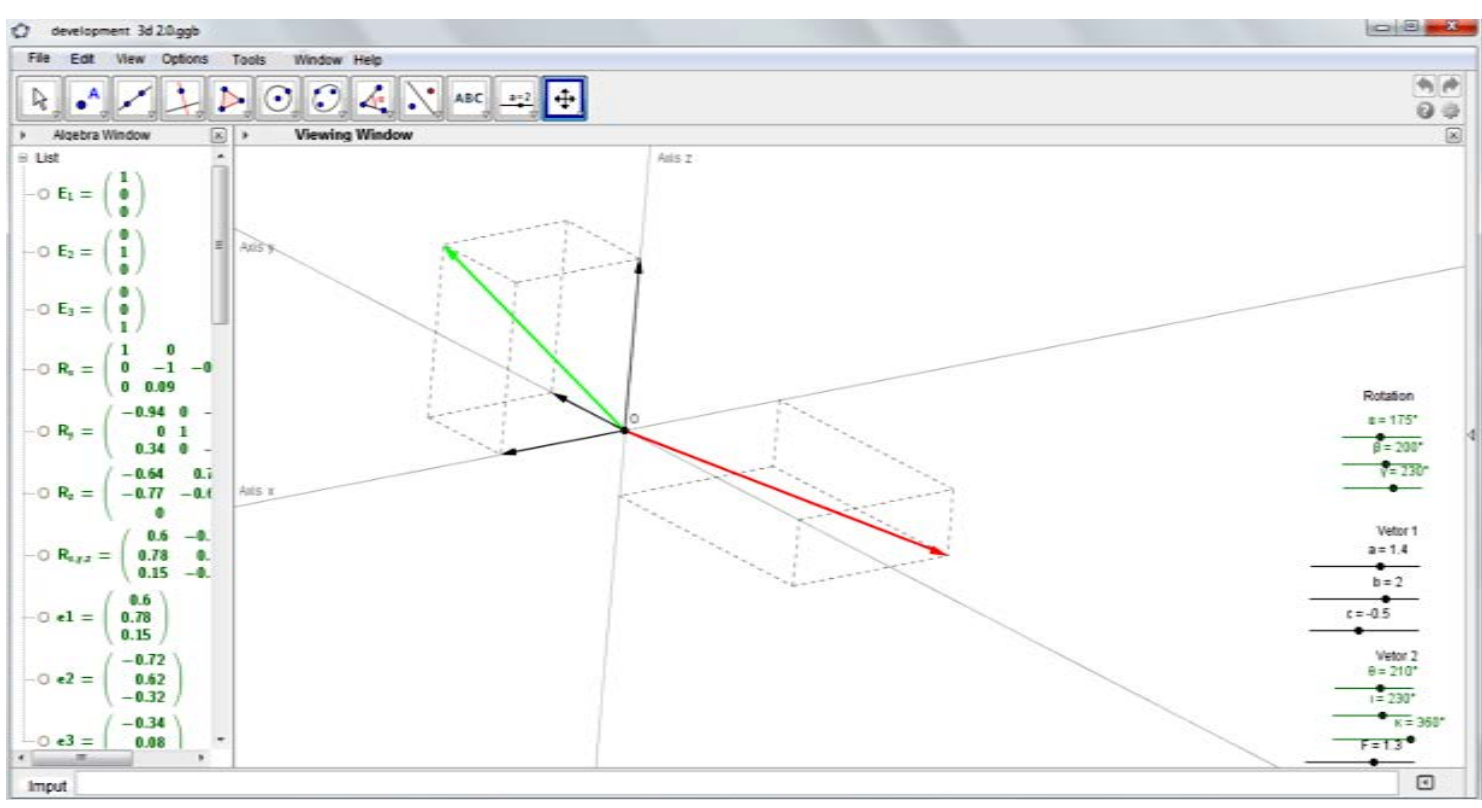

Figure 4. Decomposition of force in space. Extracted from reference: Ribeiro (2014).

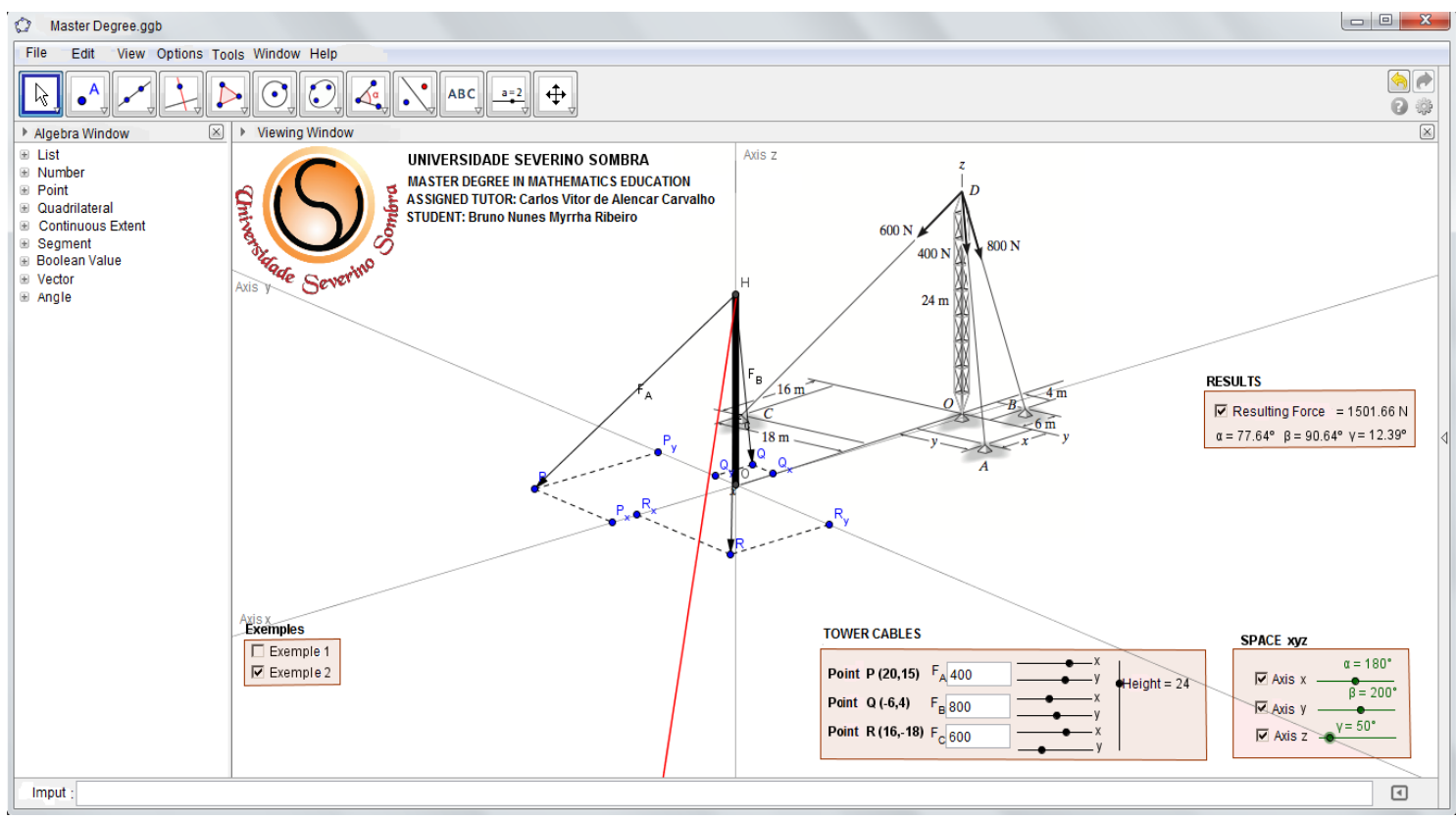

Figure 5. Applied activities. Extracted from reference: Ribeiro (2014).

\section{Discussion}

The potentially significant material is proposed with the aim to teach the calculation and representation of the forces acting on the space of vector problems in mechanics. To observe the use of the developed activity and their use in the classroom, some students of Civil Engineering, Production Engineering and Mechanical Engineering, Geraldo di Biase University Center were chosen.

The analysis was made from the characteristic clarity of information and the quality of materials which was potentially significant, particularly with respect to visualization and interactivity. For this a situation that involves a practical problem in the representation and calculation of resultant force acting on a given tower (Figure 7) is presented. 


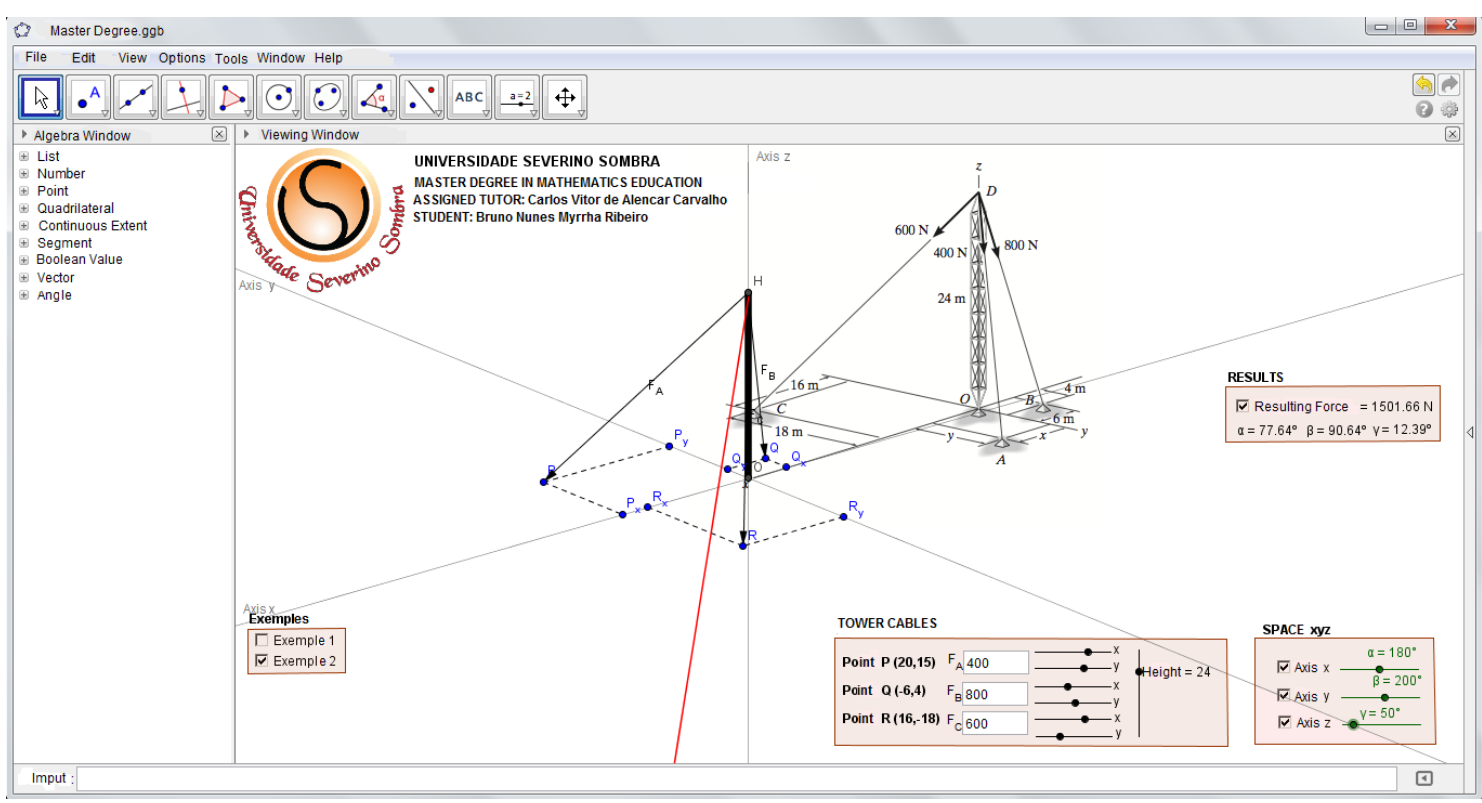

Figure 6. Applied activities. Extracted from reference: Ribeiro (2014).

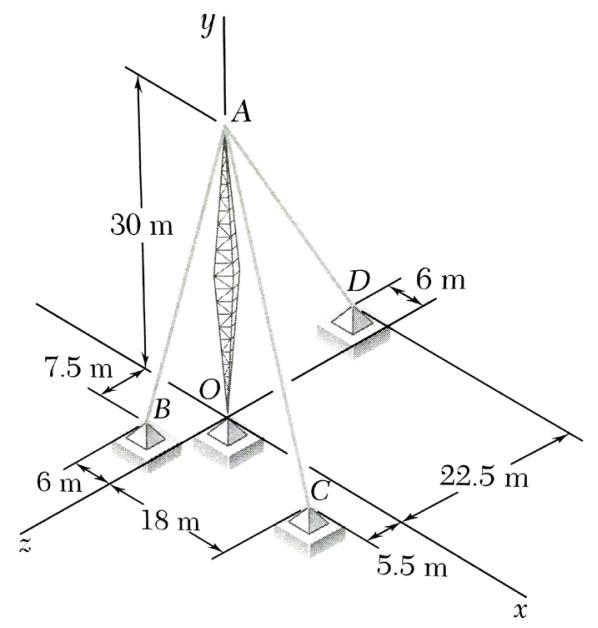

Figure 7. Structure that was used as an example in the classroom. Extracted from reference: (Beer, Johnston, \& Eisenberg, 2006).

Initially a presentation on the operation and use of GeoGebra was necessary. Subsequently, it is required to put forward the developed activity, explain its operation and which parameters should be modified, that is to say, the support points of the cable coordinates that sustain the tower.

Thus, the students made the modifications of the cable coordinates and tried to reproduce the image shown in Figure 7 and therefore to observe the value and direction of the resulting force. Figures 8-10 demonstrate moments of this investigation.

The return of the students who participated in the activity was very interesting and rewarding. It showed that we were in the right direction and that the use of technology to assist in the teaching-learning process, apart from being feasible, was an essential tool these days. Some points were highlighted: 1) the use of GeoGebra is really a facilitator. Students indicated that the software was easy to use and very simple. This is very important to motivate the participation of students who use the software; 2) The activity developed with GeoGebra software proposed in this paper clearly demonstrates dependencies between vectors, resulting in the study of vector mechanics; 3) The students suggested that new developments should be researched and investigated in engineering, such as the development of activities for teaching topics of the strength of material and of fluid mechanics. 


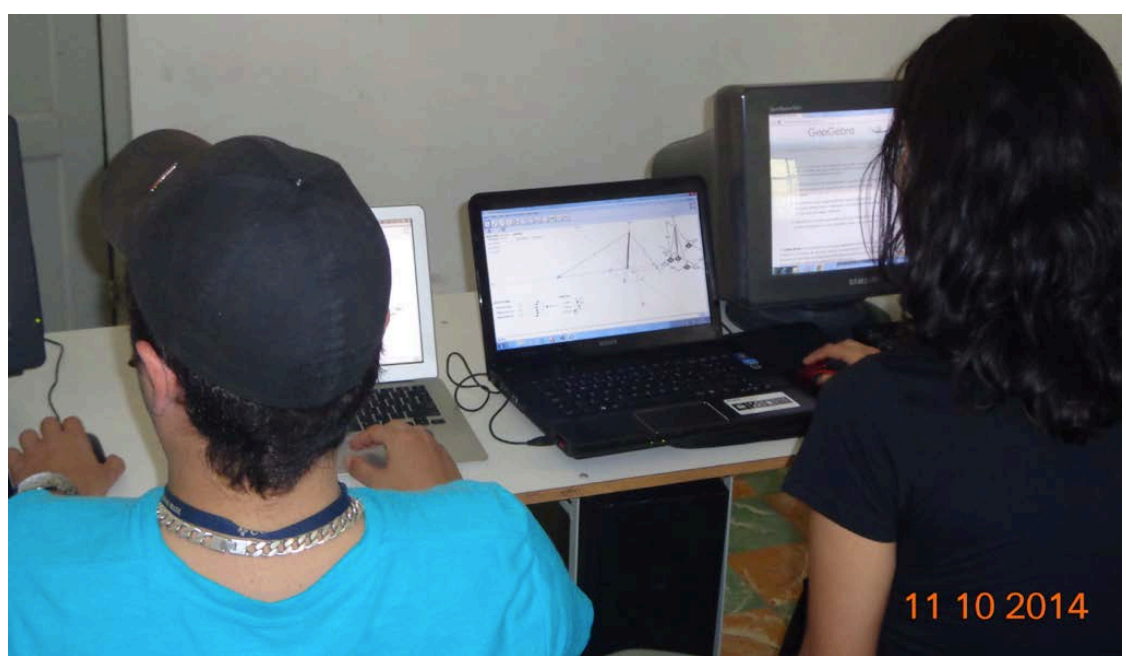

Figure 8. Students using the activity developed in GeoGebra software.

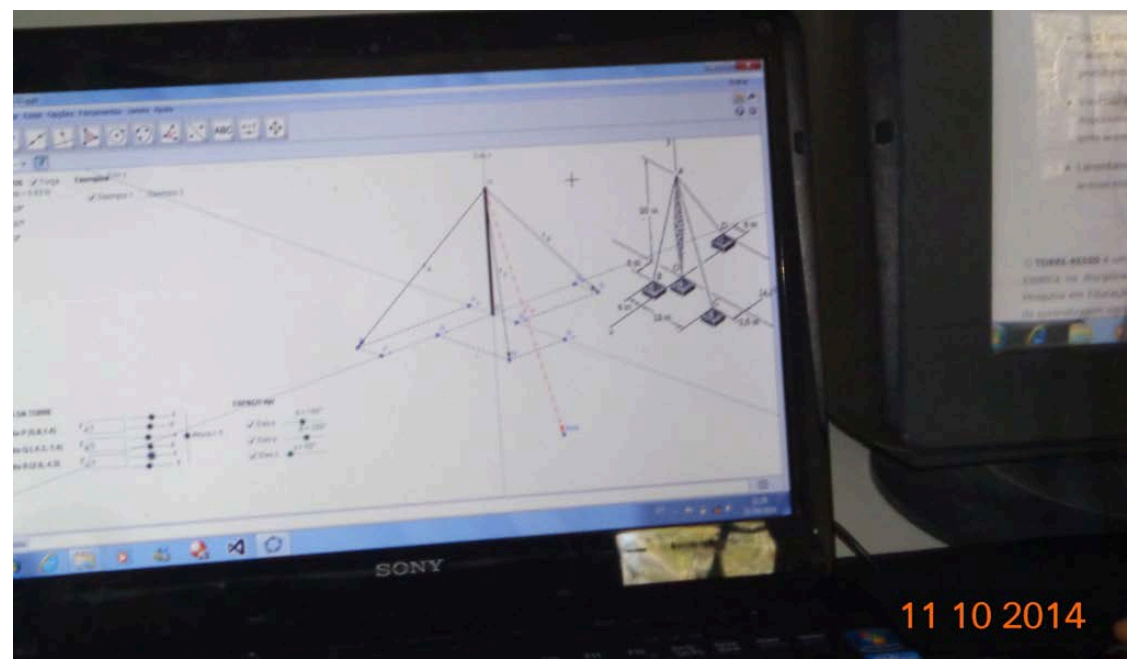

Figure 9. Students using the activity developed in GeoGebra software.

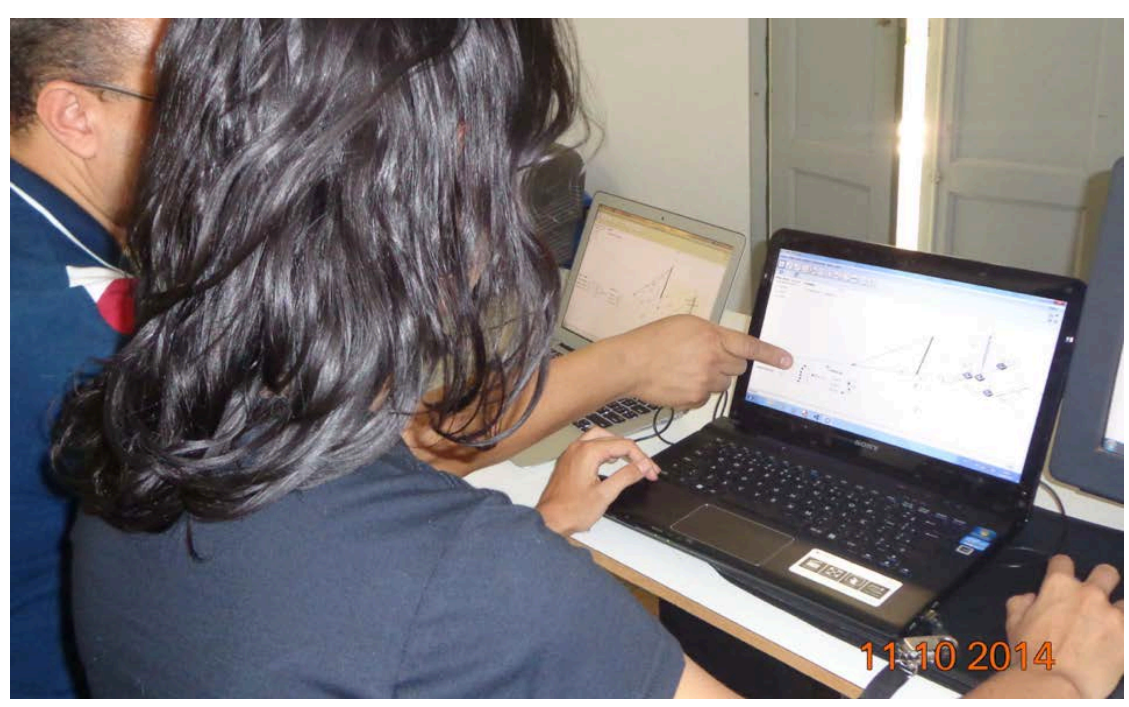

Figure 10. Students using the activity developed in GeoGebra software. 


\section{Acknowledgements}

The first author thanks CNPq for financial support (process 310282/2012-8).

\section{References}

Almeida, M. E. (2000) Prolnfo: Informática e Formação de Professores. Vol.1, Secretaria de Educação a Distância. Brasília: Ministério da Educação, Seed. 192. (Série de Estudos. Educação a Distância. ISSN 1516-2079; v.13)

Beer, F. P., Johnston, R. E., \& Eisenberg, E. R. (2006) Mecânica Vetorial para Engenheiros. Vol. Estática, 7ª edição, São Paulo: MacGraw-Hill, 619.

Valente, J. A. (1999) O computador na sociedade do conhecimento. Campinas: UNICAMP/NIED.

Moreira, M. A., \& Masini, E. F. S. (2011) Aprendizagem Significativa: A teoria de David Ausubel. $3^{\circ}$ Edição, São Paulo: Editora Centauro, 111.

Moreira, M. A. (2009) Subsídios Teóricos para o Professor Pesquisador em Ensino de Ciências-Comportamentalismo, Construtivismo e Humanismo. 1o Edição. Porto Alegre, Brazil.

Ribeiro, B. N. M. (2014) Desenvolvimento e proposta de uma unidade de ensino potencialmente significativa para tópicos de mecânica vetorial. Dissertação (Mestrado Profissional em Educação Matemática). Vassouras: Universidade Severino Sombra. 
Scientific Research Publishing (SCIRP) is one of the largest Open Access journal publishers. It is currently publishing more than 200 open access, online, peer-reviewed journals covering a wide range of academic disciplines. SCIRP serves the worldwide academic communities and contributes to the progress and application of science with its publication.

Other selected journals from SCIRP are listed as below. Submit your manuscript to us via either submit@scirp.org or Online Submission Portal.
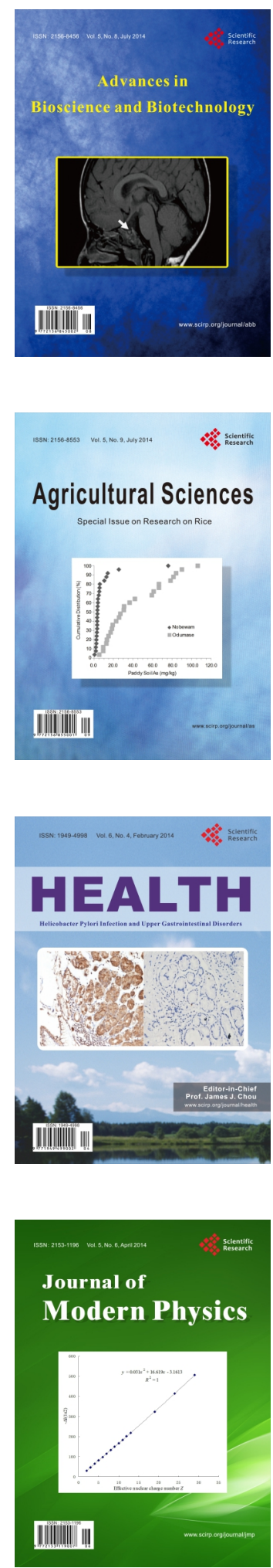
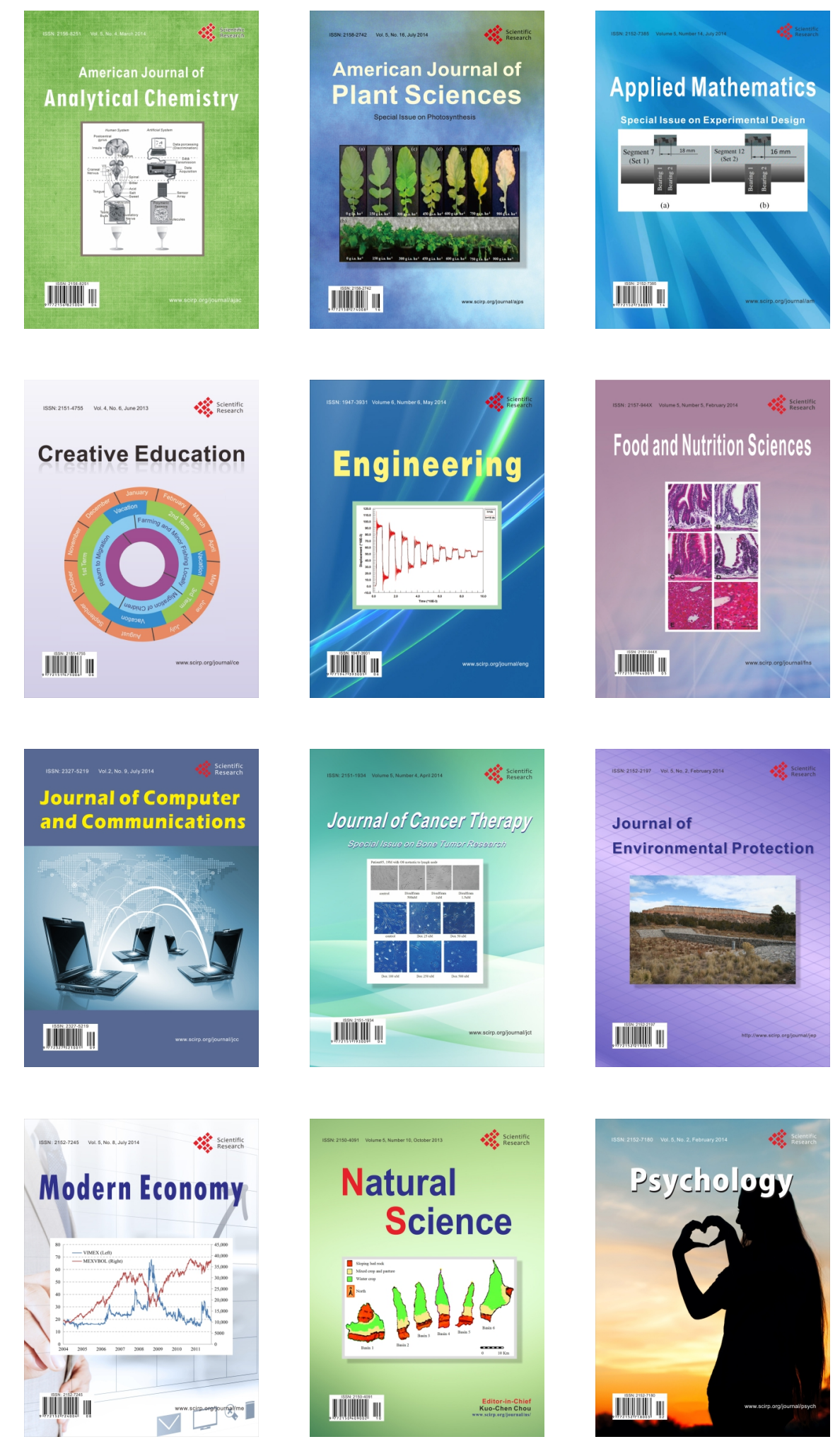